\title{
EDITORIAL
}

\section{Introducing the Science and Art in Plastic Surgery Journal}

I

$\mathrm{t}$ is with great joy and excitement that we present the Science and Art in Plastic Surgery Journal (SAPS Journal), a peer-reviewed open-access online publication and official scientific communication of the SAPS Academy.

After months well invested in planning and executing our project to procure a high-standard independent publication, we finally are able to present this new opportunity for plastic surgeons to share their work with the rest of the world.

It is our drive in constant evolution, procuring to grow the network of surgeons that share with us ideals of highest quality and innovation in research, surgery, and education.

We therefore expand the scope of our work in SAPS Academy and seek to apply our standards in rethinking traditional educational platforms to strengthen in every field of our specialty in plastic surgery.

We proudly present this journal to help and cooperate with our colleagues across the globe to spread and share their ideas.
We feel honored to have acceptance from some of the most recognized colleagues throughout the world to join the Editorial team. This will strengthen our capacity to ensure the most robust start for this new endeavor, which we are confident will grow into one of the most relevant publications in the field of plastic surgery.

Jaume Masià Ayala MD, PhD, Editor-in-Chief

Humberto Uribe Morelli MD,

Co-Editor

Juan Carlos Zambrano Bürgl, MD, MsC, FACS, Co-Editor

Hector Cesar Durán Vega, MD, Managing Editor

Jennifer Gaona Silva, MD, Managing Editor 